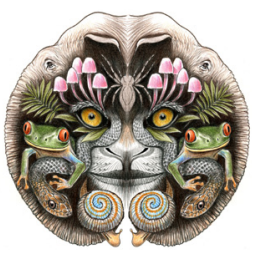

ISSN

Online 0974-7907

Print 0974-7893
The Red Panda Ailurus fulgens is associated with the eastern Himalaya, while having a global range that extends from eastern Nepal through Bhutan, India, and Burma to southern Tibet and western Yunnan Province of China (Chowdury 2001; Wang et al. 2008).

There is limited information on its distribution and status range-wide, mainly due to its elusive nature (Mahato 2010). Loss and fragmentation of its habitat, coupled with hunting, threatens the Red Panda throughout its range (Yonzon et al. 1991; Wei et al. 1999; Pradhan et al. 2001), including in Arunachal Pradesh, India (Kumar 2010). It is estimated that there are fewer than 10,000 mature individuals worldwide, and populations continue to decline (Wang et al. 2008). Due to such anthropogenic threats, Red Pandas are classified as Vulnerable under IUCN and placed in Appendix-I of CITES. In India the Red Panda is confined to the north-east in Sikkim, northern West Bengal and Arunachal Pradesh, with an unconfirmed isolated population in Meghalaya (Finn 1929: Prater 1948; Gee 1964; Choudhury 1996, 1997). Arunachal Pradesh has possibly the widest distribution of Red Pandas in India with a potential habitat of $23000 \mathrm{~km}^{2}$ hosting probably the largest population in India (Choudhury 2001).

Red Pandas are, characteristically, animals of the upper subtropical-temperate areas with their habitat typically characterized by the presence of mixed deciduous and coniferous forests with a bamboo-thicket understory (Roberts \& Gittleman 1984; Chakraborty 1999). Although it is reportedly found between 1500-4800 m (Yonzon \& Hunter 1991; Choudhury 2001), there have been no recent documented evidence of its presence in areas over

\section{A NOTE ON THE HIGH ELEVATION DISTRIBUTION RECORD OF RED PANDA AILURUS FULGENS (MAMmalia: CARNIVORA: AILURIDAE) IN TaWang District, ARUnachal Pradesh, INDIA}

\author{
Degin Dorjee ${ }^{1}$, Rajarshi Chakraborty ${ }^{2}$ \& Pijush Kumar \\ Dutta $^{3}$ \\ 1,2,3 WWF-India Western Arunachal Programme, Parvati Nagar, Tezpur, \\ Assam 784001, India \\ ${ }^{1}$ dorjedegin@gmail.com, ${ }^{2}$ rajarshicha@gmail.com (corresponding \\ author),3 pijush.dutta@gmail.com
}

$4000 \mathrm{~m}$ in most of its global range. Studies in its range countries, especially in India, have also not established its presence in areas above $4000 \mathrm{~m}$; some relevant published records are compiled in Table 1.

In the present record, a carcass of a Red Panda was found by a patrolling team of local villagers in November, 2012, at an elevation of 4325m, (27.70590N \& 91.63631E) inside Pangchen Lumpo Muchat Community Conserved Area $\left(98 \mathrm{~km}^{2}\right)$ in the remote parts of Tawang District, western Arunachal Pradesh (Image 1). The exact location was around $20-25 \mathrm{~km}$ away from the nearest road head, the village of Muchat, above the settlement of Zimithang (Image 3). Zimithang, situated on the valley floor of the Nyimjang Chu River, is around $90 \mathrm{~km}$ away from Tawang, the district headquarters. The Red Panda was caught in a snare deployed in an animal trail among the alpine scrub, where similar snares are occasionally deployed for capturing high altitude pheasants and ungulates (Image 2). There are records of Red Pandas accidentally getting caught in similar snares in Arunachal Pradesh (Choudhury 2001).

DOI: http://dx.doi.org/10.11609/JoTT.o3492.6290-2 | ZooBank: urn:Isid:zoobank.org:pub:E42BA306-7931-40E1-89E6-62A5BF7E4CAD

Editor: Angela R. Glatston, Rotterdam Zoo, The Netherlands.

Date of publication: 26 August 2014 (online \& print)

Manuscript details: Ms \# 03492 | Received 25 January 2013 | Final received 29 July 2014 | Finally accepted 02 August 2014

Citation: Dorjee, D., R. Chakraborty \& P.K. Dutta (2014). A note on the high elevation distribution record of Red Panda Ailurus fulgens (Mammalia: Carnivora: Ailuridae) in Tawang District, Arunachal Pradesh, India. Journal of Threatened Taxa 6(9): 6290-6292; http://dx.doi.org/10.11609/JoTT.o3492.6290-2

Copyright: (c) Dorjee et al. 2014. Creative Commons Attribution 4.0 International License. JoTT allows unrestricted use of this article in any medium, reproduction and distribution by providing adequate credit to the authors and the source of publication.

Funding: WWF-India and Sir Dorabji Tata Trust and The Allied Trusts

TATA HOUSING

Competing Interest: The authors declare no competing interests. SIR DORABJI TATA TRUST AND THE ALLIED TRUSTS

Acknowledgements: The authors wish to acknowledge Sir Dorabji Tata Trust and the Allied Trusts and Tata Housing Development Company Limited for supporting the conservation activities in the region. Dr. Dipankar Ghose, Director, Species \& Landscapes Division, WWF-India is also thanked for his continuous support. We thank Kamal Medhi for creating the final map for the manuscript. Other colleagues in WWF-India Western Arunachal Landscape Programme Office are also thanked for their support. Lastly, we thank the people of Pangchen valley for their tireless support in the conservation related activities. 


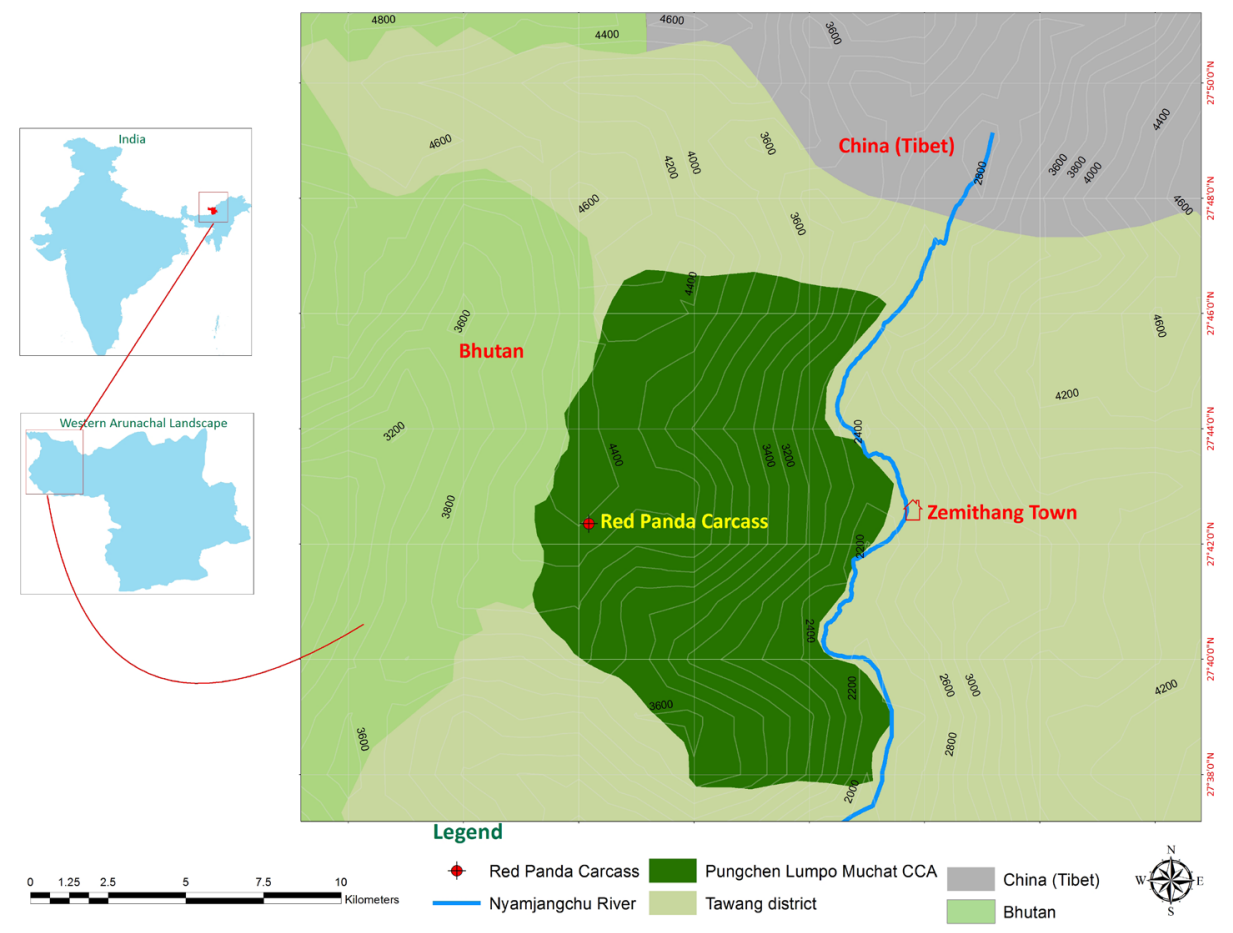

Image 1. Map of the PLUMCCA in Tawang district, Arunachal Pradesh showing the exact location of the red panda carcass. Source: Kamal Medhi/ WWF-India

Table 1. Compilation of recent published studies showing altitudinal distribution of Red Pandas in the range countries.

\begin{tabular}{|c|l|l|l|l|l|}
\hline & Study area & Country & $\begin{array}{l}\text { Elevation range } \\
\text { of study area }\end{array}$ & $\begin{array}{l}\text { Red Panda elevation } \\
\text { range from findings } \\
\text { (meters) }\end{array}$ & Reference \\
\hline I. & Dhorpatan Hunting Reserve & Nepal & $2800-5500$ & $2800-4000$ & $\begin{array}{l}\text { Panthi et al. (2012), } \\
\text { Sharma \& Belant 2009) }\end{array}$ \\
\hline II. & Ilam District & Nepal & $2400-3000$ & $2400-3000$ & Williams (2004) \\
\hline III. & Jigmi Dorjee National Park & Bhutan & $1400-7000$ & $2400-3700$ & Dorji et al. (2011) \\
\hline IV. & Woolong Nature Reserve & China & $1200-6250$ & $2600-3100$ & Reid et al. (1991) \\
\hline V. & Parts of Myanmar & Myanmar & $20-3750$ & Up to 3390 & Zaw et al. (2008) \\
\hline VI. & Barsey Rhododendron Sanctuary, Sikkim & India & $2000-4100$ & Up to 3177 & Bhutia ( 2011) \\
\hline VII. & Khangchendzonga National Park, Sikkim & India & $1300-8598$ & Up to 3800 & Sathyakumar et al. (2011) \\
\hline VIII & Three Protected Areas of East Sikkim & India & $1200-4700$ & Up to 3570 & Ghose et al. (2011) \\
\hline IX. & Singalila National Park, West Bengal & India & $2400-3636$ & $2800-3600$ & Pradhan et al. (2001) \\
\hline X. & Neora Valley National Park, West Bengal & India & $2350-3170$ & Up to 3170 & Mallick (2010) \\
\hline
\end{tabular}

The vegetation of the area, situated near a high-altitude wetland called Kemela Tso, was mostly Rhododendron scrub forest with Rhododendron thomsonii, R. anthopogon and Juniperus sp. being the dominant plant species. Presumably, the animal was using the trail for passage when it activated the snare and was caught in the neck by the noose. It was found in that position, with no distinct signs of feeding by any carnivores afterwards. From the condition of the carcass, which was absolutely dehydrated, it seemed that the animal got captured some considerable time back. Its occurrence in such a high alpine scrubland at an elevation of $4325 \mathrm{~m}$ provides one of the highest documented presence records in India. The record is unusual; especially considering the fact the area had no presence of bamboo, considered as a vital habitat as well as a diet component of the Red Panda. The nearest patch of ideal Red Panda habitat (Mixed conifer forests at $3000-3500 \mathrm{~m}$ ) is situated around $10-12 \mathrm{~km}$ away, in the lower elevations near a place called Keradumsung. While the local herders have reported Red Panda sightings along the lower portions of the CCA, there were no earlier reports of their presence in an area as high as Kemala Tso.

Considering the long distance to the tree line and their ideal coniferous habitats from the location of the carcass, it 


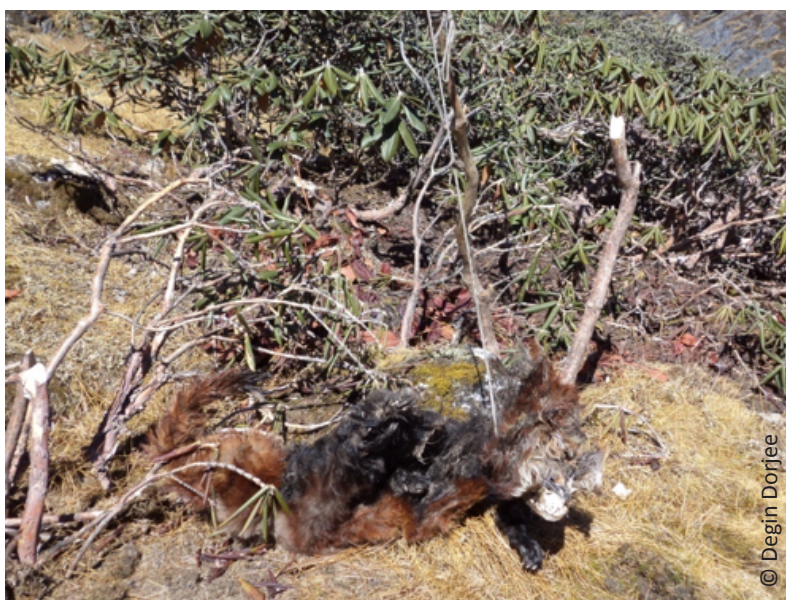

Image 2. The Red Panda accidentally caught in a snare near Kemala Tso

is interesting to note such a long transit undertaken by this particular animal, that too during the early winter months. Extensive seasonal field data on Red Panda presence throughout the CCA will be able to provide a conclusive verdict on the elevation range favoured by the Red Pandas in the area. While such incidences of casualty can be considered as a potential threat to the Red Pandas in this region, as reported, the cases are extremely sporadic and localised. With the community members being closely involved in the management of Pangchen Lumpo Muchat Community Conserved Area (PLUMCCA) and mitigation of threats to Red Panda and other wildlife, even incidences of hunting in the fragile high altitude ecosystem under their guardianship are very rare.

\section{References}

Bhutia, J.L. (2011). Current Distribution, Population Status, Habitat Characteristics and Conservation of Red Panda in Barsey Rhododendron Sanctuary, Sikkim, India. MSc Thesis. NERIST (Deemed University), Itanagar, Arunachal Pradesh, 42pp.

Chakraborty, T. (1999). Himalayan heritage: the endangered Red Panda. Himalayan Paryavaran: The Journal of the Environment Protection Society 6: 129-132.

Choudhury, A. (1996) Red Panda in Garo hills. Environ 4:21.

Choudhury, A. (1997) Red Panda Ailurus fulgens F. Cuvier in the northeast with an important record from Garo hills. Journal of the Bombay Natural History Society 94: 145-147.

Choudhury, A. (2001). An overview of the status and conservation of the Red Panda Ailurus fulgens in India, with reference to its global status. Oryx 35(3): 250-259; http://dx.doi.org/10.1046/j.13653008.2001.00181.x

Dorji, S., K. Vernes \& R. Rajanathan (2011). Habitat Correlates of the Red Panda in the temperate forests of Bhutan. PLoS One 6(10): e26483.

Finn, F. (1929) Sterndale's Mammalia of India. Thacker, Spink, Calcutta \& Simla, vii+347pp.

Gee, E.P. (1964) The Wild Life of India. Collins, London, ill+ 192pp.

Ghose, P.S., B. Sharma, R. Chakraborty \& K. Legshey (2011). Status of Red Panda in Sikkim: a case study in east Sikkim, pp. 363-378. In: Arrawatia, M.L. \& S. Tambe (eds.). Biodiversity of Sikkim - Exploring and Conserving a Global Hotspot. Information and Public Relations

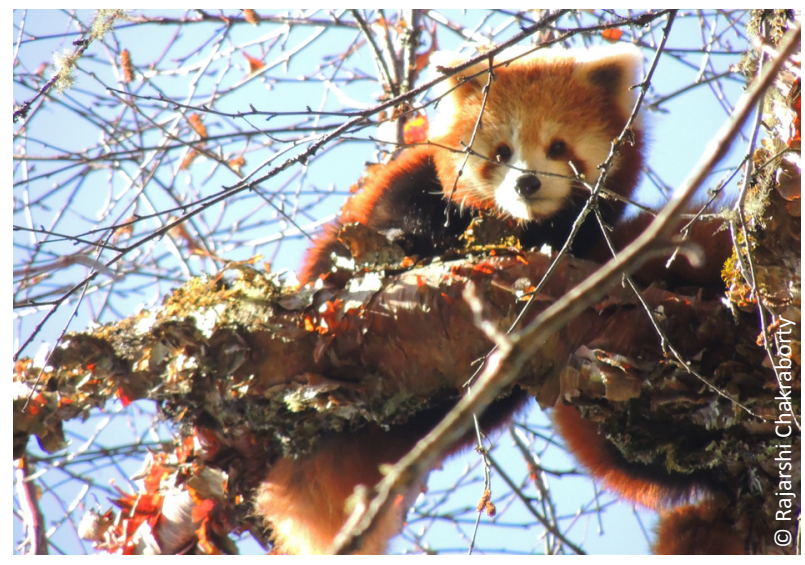

Image 3. Red Panda near Zemithang

Department, Government of Sikkim, 542pp.

Mahato, N. (2010). Distribution of the Red Panda Ailurus fulgens (Cuvier, 1825 ) in Nepal based on a predictive model. MSc Thesis. Texas State University, xiii+75pp.

Mallick, J.K. (2010). Status of Red Panda Ailurus fulgens in Neora Valley National Park, Darjeeling District, West Bengal, India. Small Carnivore Conservation 43: 30-36.

Panthi, S., A. Achyut, D. Raubenheimer, L. Jennie \& B. Adhikari (2012). Summer Diet and Distribution of the Red Panda (Ailurus fulgens fulgens) in Dhorpatan Hunting Reserve, Nepal. Zoological Studies 51(5): 701-709.

Pradhan, S., G. Saha \& J.A. Khan (2001). Ecology of the Red Panda Ailurus fulgens in the Singhalila National Park, Darjeeling, India. Biological Conservation 98(1): 11-18; http://dx.doi.org/10.1016/ S0006-3207(00)00079-3

Prater, S.H. (1948) The Book of Indian Animals. Bombay Natural History Society, Bombay, LXIX+324pp.

Roberts, M.S. \& J.L. Gittleman (1984). Ailurus fulgens. Mammalian Species 222: 1-8.

Reid, D.G., J. Hu \& Y. Huang (1991). Ecology of the Red Panda Ailurus fulgens in the Wolong Reserve, China. Journal of Zoology 225(3): 347364; http://dx.doi.org/10.1111/j.1469-7998.1991.tb03821.x

Sathyakumar, S., T. Bashir, T. Bhattacharya \& K. Poudyal (2011). Assessing mammal distribution and abundance in intricate eastern Himalayan habitats of Khangchendzonga, Sikkim, India. Mammalia 75(3): 257-268; http://dx.doi.org/10.1515/mamm.2011.023

Sharma, H.P. \& J.L. Belant (2009). Distribution and observations of Red Pandas Ailurus fulgens fulgens in Dhorpatan Hunting Reserve, Nepal. Small Carnivore Conservation 40: 33-35.

Wang, X., A. Choudhury, P. Yonzon, C. Wozencraft \& Z. Than ( 2008). Ailurus fulgens. In: IUCN 2011. 2011 I UCN Red List of threatened species. <www.iucnredlist.org> .Downloaded on $16^{\text {th }}$ January 2013.

Williams, B. (2004) Status of Red Panda in Jamuna and Mabu villages of eastern Nepal. MSc Thesis. The Faculty of the Department of Environmental Studies, San José State University, xvii+194pp.

Wei F., Z. Feng, Z. Wang \& M.Li (1999) Feeding strategy and resource partitioning between Giant and Red Pandas. Mammalia 63(4): 417429; http://dx.doi.org/10.1515/mamm.1999.63.4.417

Yonzon, P.B. \& M.L. Hunter (1991). Cheese, tourists, and Red Pandas in the Nepal Himalayas. Conservation biology 5(2): 196-202; http:// dx.doi.org/10.1111/j.1523-1739.1991.tb00124.x

Yonzon, P., R. Jones \& F. Jefferson (1991). Geographic information systems for assessing habitat and estimating population of Red Pandas in Langtang National Park, Nepal. Ambio 20(7): 285-288.

Zaw, T., S. Htun, S. Po, M. Maung, A.J. Lynam, K.T. Latt \& J.W. Duckworth (2008). Status and distribution of small carnivores in Myanmar. Small Carnivore Conservation 38: 2-28.

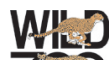

